\title{
Biodiesel vs. Diesel Oil in a Marine Engine: A Thermodynamic Study
}

\author{
Mohamed Djermouni*, Ahmed Ouadha \\ Laboratoire des Sciences et Ingénierie Maritimes, Faculté de Génie Mécanique, Université des Sciences et de la Technologie Mohamed \\ BOUDIAF d'Oran (USTO-MB), BP 1505 Oran El-M'naouar, 31000 Oran, Algérie
}

\begin{abstract}
The present comparative study deals primarily with the thermodynamic performances of the traditional fuel being used in shipping propulsion, Diesel oil and one of its alternatives, namely, the biodiesel. A thermodynamic model was developed based on the first and second law of thermodynamics. It was found that the engine running on biodiesel registers a slight improvement of its performances compared with the one running on Diesel oil in all the departments considered in this study.
\end{abstract}

\section{Introduction}

With their outstanding advantages such as high efficiency and reliability, Diesel engines are the prime mover of most sea ongoing vessels. However, tightening emission regulations combined to increasing fuel costs have led the marine industry to seek alternative competitive fuels. The search for alternative fuels is based on two main prerogatives: provide a better efficiency of the engine and reduce its environmental impact. Many fuels have been acknowledged as alternate fuels which can be utilized in marine Diesel engine. Among these fuels, biodiesel presents the advantage to be derived from different sources namely, waste oil, vegetable oils from non-edible sources, animal fat, and some underrated bioenergy feed stocks.

Ironically, the German inventor of Diesel engine Dr. Rudolf Diesel used a biofuel (peanut oil) in his prototype before shifting into petroleum Diesel, overwhelmed by some technological constraints of his era. He even stated once: "The use of vegetable oils for engine fuels may seem insignificant today. But such oils may become in course of time as important as petroleum and the coal tar products of the present time".

Nowadays, with the actual technological advance, the leaders of the industry of Diesel engines are having now a second thought to return to biodiesel fuels as a solution for fossil fuels depletion on one hand, and the pollution reduction for the other.

Diesel engines can burn low grade fuels for economic reasons, and they could be converted to operate in biodiesel fuels with practically no major modifications [1]. The combustion in internal combustion engines is counted in milliseconds, therefore, the requirements are very demanding for the combustion to be complete and very efficient in such tiny period. This fact made any oxygenated fuel such as alcohols and biodiesel very welcomed.

In this context, numerous experimental and numerical works were carried out. For example, Golovitchev and Yang [2] developed a combustion model of biodiesel (rapeseed methyl ester $\mathrm{C}_{19} \mathrm{H}_{36} \mathrm{O}_{2}$ or $\mathrm{C}_{19} \mathrm{H}_{34} \mathrm{O}_{2}$ ). The model encompasses 309 chemical species with 1472 reactions including $N O_{x}$ and soot formation mechanisms. The model was validated against experimental results using shocktube-ignition-delay data carried out on Volvo D12C direct injection Diesel engine. It has to be noted that the model could be reduced to 88 species and 363 reactions under constant volume and Diesel engine combustion. In the same year, Coronado et al. [3] carried out a comparative study between five alternative fuels and fuel blends, namely gasoline-anhydrous ethanol, conventional Diesel fuel, biodiesel (B100), Diesel-biodiesel blend (B20), and natural gas in ecological view point. The engine works according to spark ignition principle. Considering a 30\% thermal efficiency as reference for all the fuels, natural gas fuelled engine came ahead with an ecological efficiency as high as $91.95 \%$, followed by pure biodiesel (B100) with $86.75 \%$, gasoline-anhydrous ethanol blend with $82.53 \%$, and last place was for Diesel-biodiesel blend (B20) with 78.79\%. In the same context, Westbrook et al. [4] have examined experimentally the influence of four types of biodiesel on combustion, emissions, heat release, and indicated power of a direct injection Diesel engine. It was shown that the kinematic viscosity and methyl esters fatty acids saturation level are determinant for ignition delay. The latter has decreased with the increase of the saturation level and kinematic viscosity of biodiesel and promoted, however,

\footnotetext{
* Corresponding author: djermounimohamed@yahoo.fr
} 
the appearance of $N O_{x}$ emissions. Qi et al. [5] have studied experimentally the influence of injection time and rate of exhaust gas recirculation (EGR) on the combustion and emissions of Ford Lion V6 Diesel engine. The engine works on $100 \%$ soybean oil. The findings demonstrate that increasing EGR rates decreases $N O_{x}$ emissions. Moreover, under high EGR rates, engine maximum pressure decline slightly retaining the same heat release rate for partial loads. In its turn, delay of injection time enhances $N O_{x}$ emissions but it increases specific fuel consumption. Similar study was accomplished by An et al. [6]. They analysed the effect of different ultra-low sulphur Diesel-biodiesel blends with the following proportions: $0 \%$ biodiesel (D100), 10\% biodiesel (B10), 20\% biodiesel (B20), 50\% biodiesel (B50), and 100\% biodiesel (B100). The authors have found that biodiesel content increases the specific fuel consumption with $100 \%$ comparing D100 with B100, and reduces thermal efficiency at partial loads. In addition, the increase of biodiesel proportions provokes rises $C O$ emissions at low loads. However, $\mathrm{CO}$ emissions could be corrected by increasing the engine rotation speed. Lin [7] addressed the main obstacles that hinder biodiesel blends to be used in marine vessels. To name a few, the economic supremacy of conventional Diesel fuel over biodiesel fuels, lack of marine-grade biodiesel specifications that only exist for land-based automotive Diesel vehicles (EN14214 in European Union and ASTM D6751 in USA), requirement for huge amounts of biomass feedstock to satisfy the need of marine fleet, low temperature fluidity of biodiesel which restricts its use in cold regions. The author believes in the compatibility of biodiesels in maritime sector, and proposed several strategies to make this happen: establishing marine grade biodiesel specifications, enhancing the economic reliability of biodiesels by tax cuts or exemption and financial subsidy for the feedstock or the production of biodiesel, and improving low-temperature by altering the fatty acids contents in biodiesel blends and using proportions of petroleum derived fuel oil, and or additives or antifreeze agents. Harveer et al. [8] tested the effect the dependence of engine performances on the concentration of Sal Methyl Ester (SME) in its blend with conventional Diesel fuel. An increase of specific fuel consumption was recorded under an increase of volumetric concentration of SME from $13.6 \mathrm{MJ} / \mathrm{kWh}$ at $10 \% \mathrm{SME}$ to $14.8 \mathrm{MJ} / \mathrm{kWh}$ at $40 \% \mathrm{SME}$, while 13.9 MJ/kWh was realised for pure Diesel fuel. In emissions department, unburned hydrocarbons emissions were reduced from $60 \mathrm{ppm}$ for pure Diesel fuel to an average of 48 and 51 ppm under SME operating conditions. Recently, Zhang et al. [9] have conducted a series of experiments in order to determine the effect of the different constituents of biodiesels, mainly fatty acid methyl esters (FAME), when used as a fuel in a four cylinders, direct injection marine Diesel engine. It was demonstrated that the more the fatty acid methyl ester was saturated, the shorter ignition delay was obtained. However, with high kinematic viscosities, the fuel-air mixing rate was enhanced leading to better combustion performances but with the increase of $N O_{x}$ emissions. Jiaqiang et al. [10] investigated the effect of adding water and metal-based additive in the biodieselDiesel blend used as fuel for a medium speed marine Diesel engine. Various fuels blends with different proportions of biodiesel and water and cerium oxide nanoparticles were examined in this experimental study. The findings have shown that adding water to the fuel blends was advantageous in improving the fuel-air mixing quality and enhances $C O, P M, N O_{x}$, and $H C$ emissions due to the micro-explosion. However, water content up to $6 \%$ by weight affect negatively the combustion due to the increase of viscosity. In its turn, the metal-based additives improve the brake power and brake thermal efficiency along with decreasing specific fuel consumption and pollutant emissions, thanks to the improved catalytic activity that leads to a better combustion process. Gorka et al. [11] evaluated the technical suitability of the use of recycled waste lubricant oils as fuel for marine vessels tested on a full scale marine Diesel engine test bench for different engine loads and propulsion modes. They demonstrated that this alternative fuel burns rapidly with a delay at the end of combustion. Additionally, a better fuel consumption was obtained with waste lubricant oils, with a comparable thermal efficiency to the Diesel case. Regarding the pollutant emissions, a lower $\mathrm{NO}_{x}$ and $\mathrm{CO}_{2}$ emissions along with a slight increase of $C O$ and smoke emissions were recorded when using waste lubricant oils.

For the design of an engine running on various fuels, accurate thermodynamic models are needed to determine their performances as function of key operating parameters. In this study, a thermodynamic model was developed and used to investigate the effect of various engine parameters on performance characteristics of a marine Diesel engine fueled with bio-Diesel fuels.

\section{System Description}

The system beforehand represents a part of a marine propulsion system (Fig. 1). It encompasses the main engine, turbocharger compressor, turbine, and an intercooler. . Ambient air enters the compressor where its pressure and temperature rise to reach $p_{2}$, and $T_{2}$. The compressed air passes through an intercooler where it is cooled at constant pressure to $T_{3}$, by circulating fresh water. As stated earlier, dual fuel technology employs timed port injection technic, where the natural gas is injected near to the inlet valve of every cylinder of Dual Fuel engine to be mixed with incoming air under pressure from the intercooler and undergo thermodynamic power cycle. The air charge introduced in the cylinder is brought to a higher pressure and temperature via compression process (1-2). Toward the end of compression, fuel blend is injected at a high pressure marking the beginning of the combustion process, which takes place in two phases at constant volume $(2-\mathrm{x})$ and constant pressure $(\mathrm{x}-3)$. The combustion process is followed by the power stroke where work is produced by expanding the burned gases to a lower temperature and pressure (3-4). Finally, the exhaust gases are discharged (4- 
5-e) to the turbine inlet to be further expanded (5-6), and generate the power needed to drive the compressor. The compression (1-2) and the expansion (4-5) are assumed to be irreversible processes. The irreversibilities are taken into account using typical values for the isentropic efficiencies.

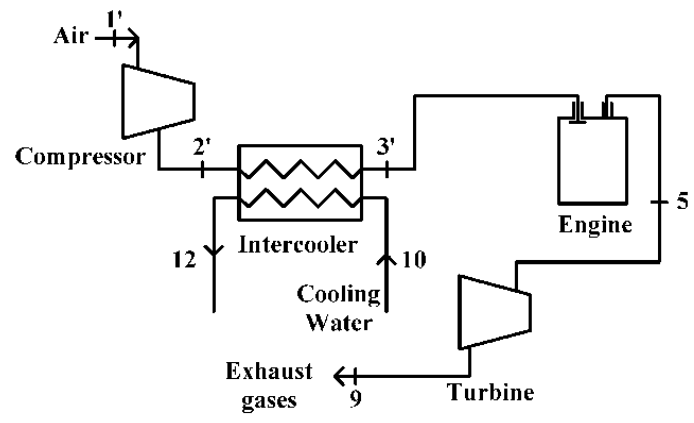

Fig. 1. Scheme of the system

\section{Thermodynamic Analysis}

In the following thermodynamic analysis, the main engine is treated, as recommended in the literature, as Diesel dual cycle, for all cases: pure Diesel, pure biodiesel, Dieselbiodiesel blends.

\subsection{Working Fluid Properties}

The working fluid differs in composition from one state to the other. It could be air, mixture of reactants, or burned gases mixture resulted from the combustion.

The specific heats at constant pressure and constant volume as function of temperature alone, as stated by ideal gas hypothesis, take a polynomial form. The constants of the polynomials are obtained by regression methods. For air, it takes a four order polynomial:

$c_{p, \mathrm{a}}=a_{0}+a_{1} T+a_{3} T^{2}+a_{4} T^{3}+a_{5} T^{4}$

and ten order polynomial for the other substances:

$c_{p, i}=a_{1} T^{10}+a_{2} T^{9}+a_{3} T^{8}+a_{4} T^{7}+a_{5} T^{6}+a_{6} T^{5}$

$$
+a_{7} T^{4}+a_{8} T^{3}+a_{9} T^{2}+a_{10} T+a_{11}
$$

Using basic expressions of thermodynamics, specific enthalpy, specific entropy, and specific exergy could be derived as follows:

$$
\left\{\begin{array}{l}
h(T)=\int c_{p}(T) \cdot d T+h_{00} \\
s(T, p)=\int \frac{c_{p}(T)}{T} d T-R \ln p+s_{00} \\
e(T, p)=\left[h(T)-h\left(\mathrm{~T}_{0}\right)\right]-T_{0}\left[\begin{array}{l}
s(T, p)- \\
s\left(T_{0}, p_{0}\right)
\end{array}\right]+e_{c h}
\end{array}\right.
$$

\subsection{Energetic Analysis}

In order to derive the performances of the thermal system from a first law point of view, fundamental thermodynamic properties must be determined at every specific point of the system. This includes specific internal energy, specific enthalpy.

First law or energetic analysis was revealed to be very useful in determining quantitative values of heat and work and their interactions within the system and with the surroundings.

\subsubsection{Turbocharger Compressor}

A large medium speed marine Diesel engine works in very lean combustion. As consequence, it requires enormous amount of air. At this stage, turbocharger compressor enters into play by providing the required quantity of air at high pressure able to penetrate in engine combustion chambers. Moreover, the use of a turbocharger compressor is determinant factor for increasing the volumetric efficiency of reciprocating internal combustion engine. Since there are no important changes in the operation of compressor in given period time, these equipments are often treated with sufficient accuracy as control volumes at steady state.

The compressor outlet temperature is calculated in two steps: calculating the isentropic temperature $\left(s_{2}=s_{1}\right)$, and then using the definition the isentropic efficiency to calculate the actual temperature.

$\eta_{i s, \text { comp }}=\frac{h_{2 s}-h_{1}}{h_{2}-h_{1}}$

The power needed by compressor is defined as:

$\dot{W}_{c}=\dot{m}_{a}\left(h_{2}-h_{1}\right)$

\subsubsection{Intercooler}

Pressurized hot air stream produced by the compressor has potential to a further increase its density by passing it through an intercooler. Thus, the engine volumetric efficiency enhances.

The intercooler ensured its mission by circulating fresh water at temperature $T_{10}$. The water absorbs heat from air stream, and returned to sea water-fresh water cooler in order to drop its temperature again to $T_{10}$.

The air temperature at the exit of the intercooler, $T_{3}$, is calculated using the following expression:

$\dot{H}_{3}=\varepsilon \dot{H}_{10}+\dot{H}_{2}(1-\varepsilon)$

where $\varepsilon$ denotes the intercooler effectiveness defined by:

$\varepsilon=\frac{\dot{H}_{2}-\dot{H}_{3}}{\dot{H}_{2}-\dot{H}_{10}}$

\subsubsection{Engine}

The engine can operate using blend of Diesel-biodiesel at any proportions. As stated earlier, the engine could be modelled with mixed cycle when it undergoes four processes: compression of air, followed by combustion process that appears after the injection fuel where the chemical energy is released in form of heat. The resulted hot gases exchange (produce) work as consequence of its 
expansion. The burned gases find their way to the exhaust valve accomplishing the exhaust stroke and closing the cycle.

The thermodynamic magnitudes, i.e. heats and works exchanged are derived considering a closed cycle energetic balance:

$\dot{W}_{1-2}=\dot{m}_{t}\left(h_{2}-h_{1}\right)$

A one step combustion equation is adopted in the present study:

$$
\begin{aligned}
& \left(n_{B} C_{19} H_{36} O_{2}+n_{D} C_{10.8} H_{18.7}\right)+\frac{a_{t h}}{\phi}\left(O_{2}+3.76 N_{2}\right) \\
& \rightarrow n_{1} \mathrm{CO}_{2}+n_{2} H_{2} \mathrm{O}+n_{3} N_{2}+n_{4} O_{2}+n_{5} H_{2}+n_{6} \mathrm{CO}
\end{aligned}
$$

The composition of products mixture is obtained using numerical method assuming that the mixture is at equilibrium.

Heat loss through cylinder walls, combustion efficiency, and mixture thermodynamic conditions are the main factor that affects the temperature of end combustion. In this purpose, Woschni heat transfer correlation was chosen over the other correlations [Heywood]:

$h_{0}=3.26 L^{-0.2} P_{a v r}{ }^{0.8} T_{a v r}{ }^{-0.55} U^{0.8}$

and the heat loss can be calculated by:

$\dot{Q}_{\text {loss }}=h_{0} A\left(T_{3}-T_{w}\right)$

It is noted that, to determine the temperature of the end of combustion, the following condition must be satisfied:

$\dot{m}_{f} \eta_{\text {comb }} L H V_{\text {Blend }}-\dot{Q}_{\text {loss }}=\dot{m}_{t}\left(h_{3}-h_{x}+u_{x}-u_{2}\right)$

where $\eta_{\text {comb }}$ is the combustion efficiency, and $L H V_{\text {Blend }}$ is the lower heating value of fuel blend defined as follows:

$Q_{L H V, b}=m_{f}\left(\right.$ Bio $_{\%} L H V_{\text {Bio }}+\left(1-\right.$ Bio $\left.\left._{\%}\right) L H V_{\text {Dies }}\right)$

where $B i o \%$ is defined as the mass ratio of biodiesel over Diesel:

$$
\mathrm{Bio}_{\%}=\frac{m_{\text {Bio }}}{\left(m_{\text {Dies }}+m_{\text {Bio }}\right)}
$$

The high enthalpy content burned gases leave their heat in exchange of work production as stated by the following formula:

$$
\dot{W}_{3-4}=\dot{m}_{t}\left(h_{3}-h_{4}\right)
$$

As imposed by Carnot principle, some heat must be exchanged to the cold reservoir:

$$
\dot{Q}_{4-1}=\dot{m}_{t}\left(u_{4}-u_{1}\right)
$$

The net work produced by the engine and its energetic efficiency are given by equation (17) and (18):

$$
\begin{gathered}
\dot{W}_{\text {engine }}=\dot{W}_{3-4}-\dot{W}_{1-2} \\
\eta_{\text {en }}=\frac{\dot{W}_{\text {engine }}}{\dot{m}_{f} L H V_{\text {Blend }}}
\end{gathered}
$$

\subsubsection{Turbine}

Principal driver of the compressor, it produces the necessary work from the exhaust gases coming from the main engine by expanding them to a lower temperature and pressure.

It is expected that work developed by the turbine to be higher than the one of the compressor to overcome mechanical losses, and to ensure the power needed by the compressor. The work developed by the turbine is defined as

$\dot{W}_{\text {Turbine }}=\dot{m}_{t}\left(h_{5}-h_{6}\right)$

\subsection{Exergetic Analysis}

Traditionally, the performances of marine engines have been widely assessed using the first law of thermodynamics. This approach takes into account only the quality of energy. However, in addition to the quantity of energy, the quality of energy is an important indicator for energy utilization. Unfortunately, the quality of energy cannot be obtained using only the first law of thermodynamics. Accordingly, the second law of thermodynamics, through the concept of exergy, can achieve this task by providing detailed information on the thermodynamic processes during an engine cycle. In particular, the sources and magnitudes of the energy wasted

\begin{tabular}{|c|c|c|}
\hline Component & Exergy destruction & Exergy Efficiency \\
\hline Compressor & $\dot{E}_{d, \text { compressor }}=\dot{W}_{\text {compressor }}+\left(\dot{E}_{1^{\prime}}-\dot{E}_{2^{\prime}}\right)$ & $\eta_{\text {ex,compressor }}=\left(\dot{E}_{1^{\prime}}-\dot{E}_{2^{\prime}}\right) / \dot{W}_{\text {compressor }}$ \\
\hline Intercooler & $\dot{E}_{d, \text { Intercooler }}=\left(\dot{E}_{2}-\dot{E}_{3}\right)-\left(\dot{E}_{12}-\dot{E}_{10}\right)$ & $\eta_{\text {ex,compressor }}=\left(\dot{E}_{12}-\dot{E}_{10}\right) /\left(\dot{E}_{2^{\prime}}-\dot{E}_{3}\right)$ \\
\hline \multirow{4}{*}{ Engine } & $\dot{E}_{d, \text { comp }}=T_{0} \dot{S}_{\text {gen }, \text { comp }}+\left(\dot{Q}_{\text {comp }} / T_{w}\right)$ & \multirow{4}{*}{$\eta_{e x, \text { engine }}=\frac{\dot{W}_{\text {engine }}}{E_{c h, f}}$} \\
\hline & $\dot{E}_{d, \text { comb }}=T_{0} \dot{S}_{g e n, c o m b}+\left(\dot{Q}_{c o m b} / T_{w}\right)$ & \\
\hline & $\dot{E}_{d, \exp }=T_{0} \dot{S}_{g e n, \exp }+\left(\dot{Q}_{\exp } / T_{w}\right)$ & \\
\hline & $\dot{E}_{d, e x-b l}=T_{0} \dot{S}_{g e n, \mathrm{ex}-\mathrm{bl}}+\left(\dot{Q}_{e x-b l} / T_{w}\right)$ & \\
\hline Turbine & $\dot{E}_{d, \text { turbine }}=\left(\dot{E}_{1^{\prime}}-\dot{E}_{2^{\prime}}\right)-\dot{W}_{\text {turbine }}$ & $\eta_{\text {ex,compressor }}=\dot{W}_{\text {turbine }} /\left(\dot{E}_{1^{\prime}}-\dot{E}_{2^{\prime}}\right)$ \\
\hline
\end{tabular}
in the system can be evaluated, and methods to reduce it can be provided.

The energy and exergy balances were applied to each component of the system and the results obtained are summarized in Table 1.

Table 1. Exergy destruction and exergetic efficiency of thermal components 


\section{Results and Discussions}

As stated previously, the aim of this study is to thermodynamically compare the performance of Diesel oil and a biodiesel in a marine Diesel engine. Comparison has been carried out over engine compression ratio $\left(r_{\mathrm{c}}\right)$ ranging from 2 to 30 , engine speed $(N)$ ranging from 200 to $700 \mathrm{rpm}$, ambient temperature $\left(T_{I}\right)$ ranging from 288 to $328 \mathrm{~K}$, and compressor pressure ratio $\left(r_{\mathrm{p}}\right)$ ranging from 2 to 5.5 (Table 2). The variation of these parameters has been carefully selected in order to remain within the typical operating conditions of turbocharged marine engines.

Figure 2 depicts the behavior of engine brake power when plotted against its efficiency for compression ratios ranging from 2 to 30, and three Diesel-biodiesel blend compositions. Here it shows a loop shapes, where the brake power increases steadily to reach a maximum for maximum efficiency until an optimum compression ratio due to increase of temperature of end compression, and therefore, the maximum temperature of the cycle.

As compression ratio increases beyond optimum compression ratio both power and efficiency start to decrease under the influence of the increase of power consumed in compression process and the decline of difference between end compression and end combustion temperatures, translated by the decrease of potential to produce heat in combustion process. In its turn, biodiesel content seems, for the condition taken in this study, to improve thermodynamic performances of the engine due to oxygen content and better charge mixing rates in combustion chambers.

Table 2. Inputs of Engine Design and Operating Parameters

\begin{tabular}{ll}
\hline Engine & \\
Number of cylinders & 18 \\
Bore $(B) /$ Stroke $(S), m m$ & $510 / 600$ \\
Engine compression ratio $\left(r_{c}\right)$ & $2-30$ \\
Rotation speed $(N), r p m$ & $200-700$ \\
Equivalence ratio $(\Phi)$ & $0.35-0.7$ \\
Isentropic efficiences, $\left(\eta_{\text {comp }}, \eta_{\text {exp }}\right)$ & 0.97 \\
Biodiesel percentage, Bio\%, $\%$ & $0-100$ \\
Turbocharger & \\
Ambient temperature $\left(T_{1}\right), K$ & $288-328$ \\
Compressor pressure ratio $\left(r_{p}\right)$ & $2-5.5$ \\
Isentropic efficiences, $\left(\eta_{\text {char }}, \eta_{\text {tur }}\right)$ & 0.8 \\
\hline
\end{tabular}

The brake power and energetic efficiencies of the engine were tested for a range of ambient temperatures that could be met in some areas in different seasons, and were tested with respect of the rotation speed. As shown in Fig. 4, a slight decline of both efficiencies was recorded with the increase of ambient temperature. This is the direct consequence of the fall of air density supplied to the engine. In its turn, engine speed raises energy and exergy efficiencies. This could be referred to the lower heat loss through cylinder walls due to the lesser time available for the cycle.

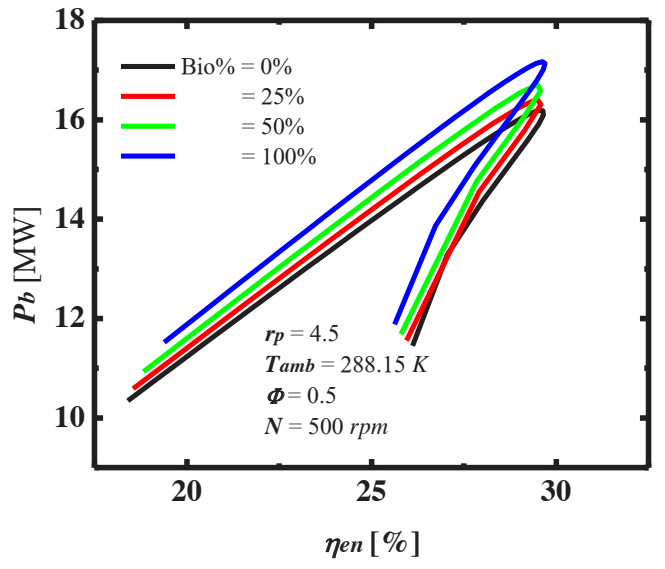

Fig. 2. Combined influence of compression ratio and biodiesel percentage on brake power and energetic efficiency

a)

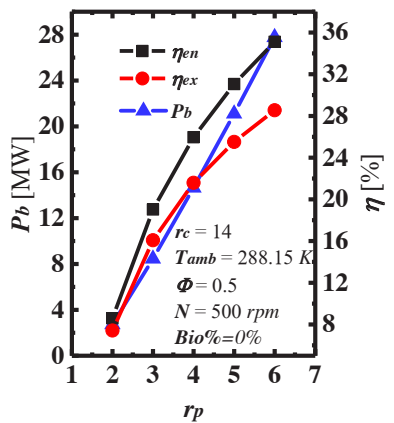

Fig. 3. Influence of compressor pressure ratio on thermodynamic performances of the engine for: $a$ ) $B i 0 \%=0 \%$, and b) $B i 0 \%=100 \%$

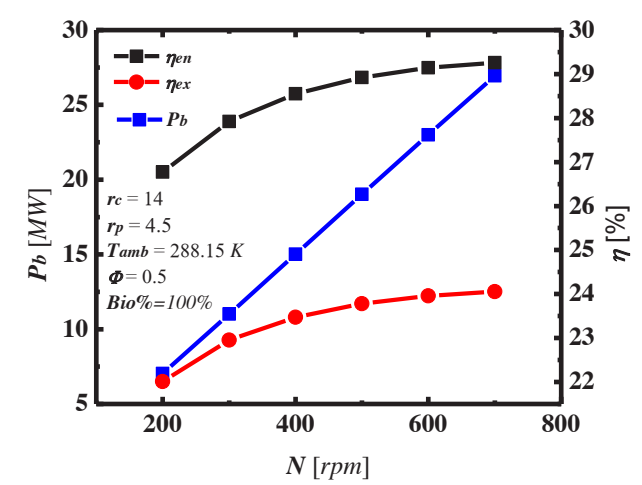

Fig. 4. Combined influence of ambient temperature and rotation speed on thermodynamic performances of the engine.

Figure 5 shows the distribution of exergy destructed in compression, combustion, expansion, and exhaust in both fuel compositions: $100 \%$ Diesel and 100\% biodiesel. The ranking of most destructive process is similar of both cases, where the combustion process causes the highest rates of irreversibilities with almost $80 \%$. This is due to irreversibilities involved in chemical reaction of the combustion and higher gradients of temperature and pressure and heat transfer through cylinder walls. 
Compression process came second with $15.16 \%$ and $15.98 \%$ for $\mathrm{BiO}^{2}=100 \%$ and $0 \%$, respectively. That comes from from friction, and higher temperature and pressure difference, which generates more entropy, and thus, more exergy destruction. Expansion process contributes with some $4 \%$ that stems mainly from friction and temperature and pressure gradients. Finally, exhaust process occupies the last place with $1.25 \%$ and $1.3 \%$ for case "a" and "b", respectively.

The rates of exergy destruction within system components for three rotation speeds are plotted in fig. 6. It is observed that increasing engine rotation speed increases friction losses, a highly exergy dissipative phenomena. Moreover, high rotation speeds affect negatively the combustion process by decreasing its efficiency, and co and unburned hydrocarbon are formed which decrease the potential of extracting heat, necessary to produce work.

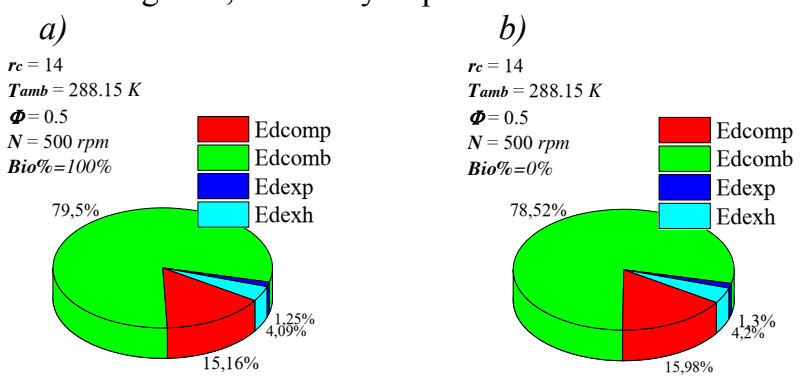

Fig. 5. Exergy distribution in internal processes of engine for: a) $100 \%$ biodiesel, and b) $0 \%$ biodiesel.

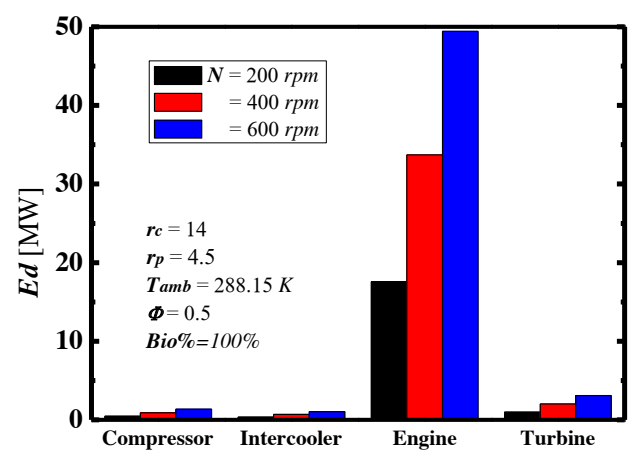

Fig. 6. influence of rotation speed on exergy destruction in system components

\section{Conclusions}

This paper has underlined the behaviour of the main engine thermodynamic performances relating to typical engine parameters such as: compression ratio, ambient temperature, rotation speed, equivalence ratio, and biodiesel percentage. The results obtained in this work, reflects the high potential of using biodiesel as fuel in marine Diesel engines. Similarly, the pressure ratio is keyword for better energetic and exergetic performances. It enhances air induction in engine cylinders, and, improves the volumetric efficiency. In its turn, rotation is another key factor for enhancing thermodynamic performances of the engine.

Combustion process in the engine has proven, once more, to be the most destructive with almost $80 \%$ of the exergy destruction in the engine. The later is responsible for $85 \%$ of the total exergy destruction in the system at $T_{a m b}=288.15 \mathrm{~K}, r_{p}=4.5, N=500 \mathrm{rpm}$, and $\phi=0.5$.

\section{References}

1. S. Jaichandarl, K. Annamalai, J. Sust. Energy Env., 2, 71-75 (2011)

2. V. I. Golovitchev, J. Yang, Biotech. Adv., 27, 641655 (2009)

3. C. R. Coronad, Jr. J. A. de Carvalho, J. T. Yoshioka, J. L. Silveira, Appl. Thermal Eng., 29, 1887-1892 (2009)

4. C. K. Westbrook, C. V. Naik, O. Herbinet, W. J. Pitz, M. Mehi, S. M. Sarathy, H. J. Curran, Combustion Flame, 158, 742-755.

5. D. Qi, M. Leick, Y. Liu, C.-f. F. Lee, Fuel, 90, 18841891 (2011)

6. C.-Y. Lin, Mar. Policy, 40, 84-90 (2013)

7. S. P. Harveer, N. Kumar, Y. Alhassan, Energy Convers. Manage., 90, 146-153 (2015)

8. Y. Zhang, W. Tao, Z. Li, Y. Qian, X. Lu, Appl. Thermal Eng., 131, 565-575 (2018)

9. E. Jiaqiang, Z. Zhiqing, C. Jingwei, P.M. inhHieu, Z. Xiaohuan, P. Qingguo, Z. Bin, Y. Zibin, Energy Convers. Manage., 169, 194-205 (2018)

10. G. Gorka, M. Leopoldo, C. B. Oihane, C. Manuel, A. Sendoa, U. Zigor, Fuel, 235, 259-268 (2019)

11. John B. Heywood, Internal Combustion Engine Fundamentals (McGraw-Hill, New York, 1988) 